\title{
Effects of Interstimulus Interval and Contingency on Classical Conditioning of the Aplysia Siphon Withdrawal Reflex
}

\author{
Robert D. Hawkins, Thomas J. Carew, ${ }^{1}$ and Eric R. Kandel \\ Howard Hughes Medical Institute, Center for Neurobiology and Behavior, College of Physicians and Surgeons, \\ Columbia University, and The New York State Psychiatric Institute, New York, New York 10032
}

The siphon withdrawal reflex of Aplysia undergoes differential classical conditioning with cutaneous stimulation of the siphon or mantle shelf as the discriminative conditioned stimuli $\left(\mathrm{CS}^{+}\right.$ and $\mathrm{CS}^{-}$) and shock to the tail as the unconditioned stimulus (US). The refiex has proved to be useful for analyzing the neural mechanisms of conditioning. To test the generality of this experimental system, we have begun to compare the properties of conditioning in Aplysia with those of conditioning in vertebrates. We first examined the effect of the interstimulus interval (ISI) by varying the time between presentation of the $\mathrm{CS}^{+}$and the US in different groups of animals. Significant differential conditioning was obtained when the onset of the $\mathrm{CS}^{+}$preceded the onset of the US by $0.5 \mathrm{sec}$, and marginal conditioning was obtained when the ISI was 1.0 sec. By contrast, no significant conditioning occurred when the $\mathrm{CS}^{+}$preceded the US by 2,5 , or $10 \mathrm{sec}$, when the onsets of the stimuli were simultaneous, or when US onset preceded the $C^{+}$by $0.5,1.0$, or 1.5 sec (backward conditioning).

We next examined the effect of contingency by giving one group of animals normal differential conditioning, and a second group the same training but with additional USs inserted between the paired trials. Presentation of these additional USs reduced the degree to which the US was contingent on the $\mathrm{CS}^{+}$, but did not change the number of pairings. Animals receiving normal training again showed significant conditioning, whereas animals receiving additional USs showed no conditioning.

The results of these experiments indicate that conditioning of the Aplysia siphon withdrawal reflex is similar to conditioning in vertebrates in two major respects: the effects of interstimulus interval and contingency. It may therefore be possible to begin to analyze the neural mechanisms of these features of conditioning in Aplysia.

The Aplysia gill and siphon withdrawal reflex has proved to be a useful system for studying the neural mechanisms of several types of learning (see Kandel and Schwartz, 1982, for a review). Recently, classical conditioning of that reflex has been demonstrated (Carew et al., 1981, 1983), and the mechanism of the conditioning has been analyzed on the cellular level (Abrams et al., 1983; Hawkins et al., 1983; Kandel et al., 1983). In this paper we describe experiments aimed at achieving a better characterization of conditioning of the reflex on the behavioral level. This is important for two reasons. First, a further characteriza-

Received Aug. 12, 1985; revised Nov. 8, 1985; accepted Dec. 5, 1985.

This work was supported by grants from the McKnight Foundation and the System Development Foundation. We thank L. Katz and K. Hilten for help in preparation of the figures and $\mathrm{H}$. Ayers for preparing the manuscript.

Correspondence should be addressed to Robert D. Hawkins, Center for Neurobiology and Behavior, Columbia University, College of Physicians and Surgeons, 722 West 168 th Street, New York, NY 10032.

Present address: Department of Psychology, Yale University, P.O. Box 11A, Yale Station, New Haven, CT 06520.

Copyright $\odot 1986$ Society for Neuroscience $0270-6474 / 86 / 061695-07 \$ 02.00 / 0$ tion of the behavioral phenomena can place constraints on possiblc ccllular mechanisms of the learning. Second, this characterization can test the generality of our experimental system. The more similar conditioning in Aplysia and in vertebrates is on the behavioral level, the more likely it would seem that basically similar neuronal mechanisms might be involved in these different species.

Studies of learning in vertebrates have revealed two basic features of conditioning that distinguish it from nonassociative learning such as habituation and sensitization. The first of these is contiguity, which refers to the temporal pairing of stimuli. Thus, conditioning of many discrete skeletal responses, such as the rabbit nictitating membrane response, is optimal if the conditioned stimulus (CS) is paired with and precedes the unconditioned stimulus (US) by approximately $0.5 \mathrm{sec}$, whereas less or no conditioning occurs if the two stimuli are presented separated in time or if the US precedes the CS (for reviews, see Gormezano, 1972; Kimble, 1961; Mackintosh, 1974). Previous experiments have shown that reliable conditioning of the Aplysia siphon withdrawal reflex occurs if the CS (a weak cutaneous stimulus to the siphon or mantle) precedes the US (tail shock) by $0.5 \mathrm{sec}$ (Carew et al., 1981, 1983). In the experiments described in the first part of this paper, we investigated the effect of temporal contiguity by systematically varying the interval between presentation of the CS and the US (the interstimulus interval).

A second basic feature of vertebrate conditioning is contingency, which refers to the degree to which one stimulus predicts another (Kamin, 1969; Rescorla, 1967). One way in which the effect of contingency has been demonstrated is to present extra, unpaired, or unpredicted USs during training. This procedure decreases the degree to which the US is contingent on the CS, and decreases conditioning (Rescorla, 1968). In the experiments described in the second part of this paper, we tested whether this effect also occurs in conditioning of the Aplysia siphon withdrawal reflex.

Preliminary results from some of these experiments have been reported previously (Hawkins et al., 1983; Kandel et al., 1983).

\section{Materials and Methods \\ Aplysia californica weighing 150-300 gm were obtained from Pacific Biomarine (Venice, CA), Sea Life Supply (Sand City, CA), or Marine Specimens Unlimited (Pacific Palisades, CA). Animals had their para- podia surgically removed to permit visualization of the entire siphon 1 or more $\mathrm{d}$ after arrival, and they were housed in individual perforated circular pans in a 200 gallon aquarium for at least 3 more d before an experiment was begun (for details, see Carew et al., 1981). A differential conditioning procedure based on that described by Carew et al. (1983) was used. In most experiments, one CS was a light tactile stimulus applied to the siphon with a nylon bristle, and the other CS was a weak electric shock $(10 \mathrm{~mA}, 60 \mathrm{~Hz} \mathrm{AC}$, for $0.5 \mathrm{sec})$ applied to the mantle shelf with bipolar capillary electrodes. The US was a stronger electric shock ( $75 \mathrm{~mA}, 60 \mathrm{~Hz} \mathrm{AC}$, for $1.0 \mathrm{sec}$ ) applied to the tail with capillary}




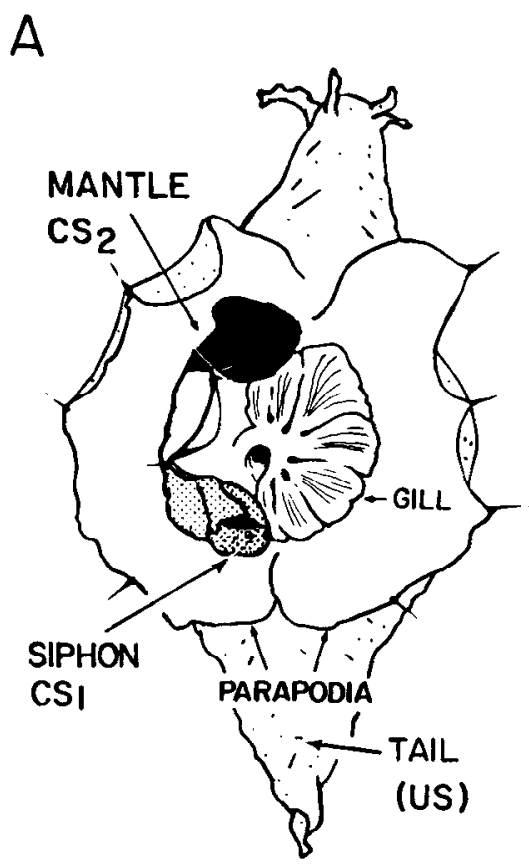

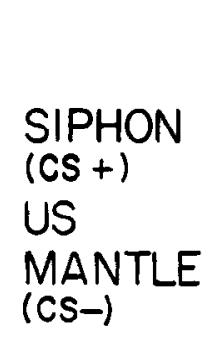
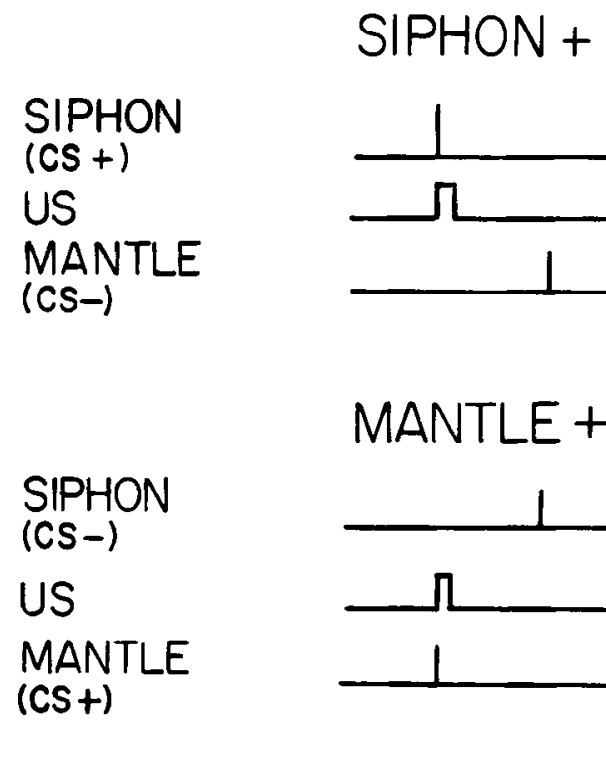
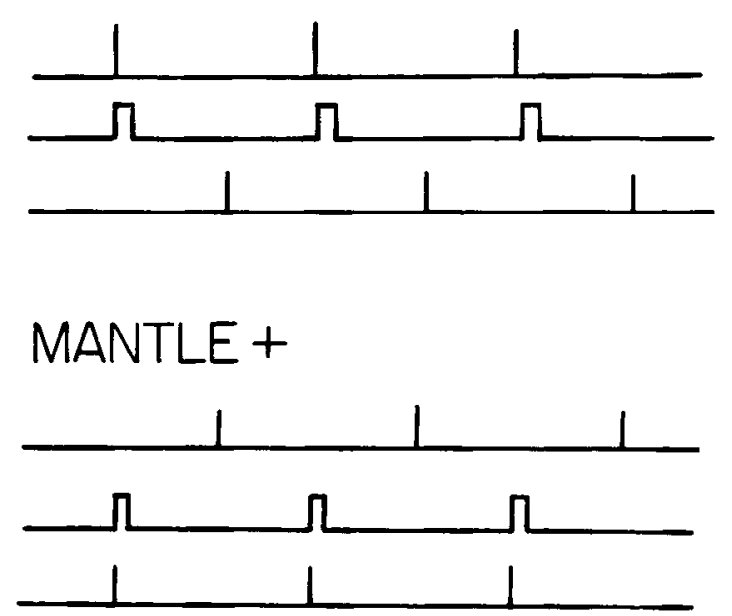

Figure 1. Differential conditioning procedure. A, Dorsal view of an Aplysia illustrating the two sites used to deliver conditioned stimuli: the siphon and the mantle shelf. The unconditioned stimulus (US) was an electric shock delivered to the tail. For illustrative purposes, the parapodia are shown intact and retracted. However, the behavioral studies were all carried out with freely moving animals whose parapodia were surgically removed. $B$, Differential conditioning paradigm. One group (siphon $\left.{ }^{+}\right)$received the siphon $C S\left(C S^{+}\right)$paired with the US and the mantle CS (CS $\left.S^{-}\right)$ specifically unpaired with the US. The other group (mantle $e^{+}$) received the mantle stimulus as the $\mathrm{CS}^{+}$and the siphon stimulus as the $\mathrm{CS}^{-}$.
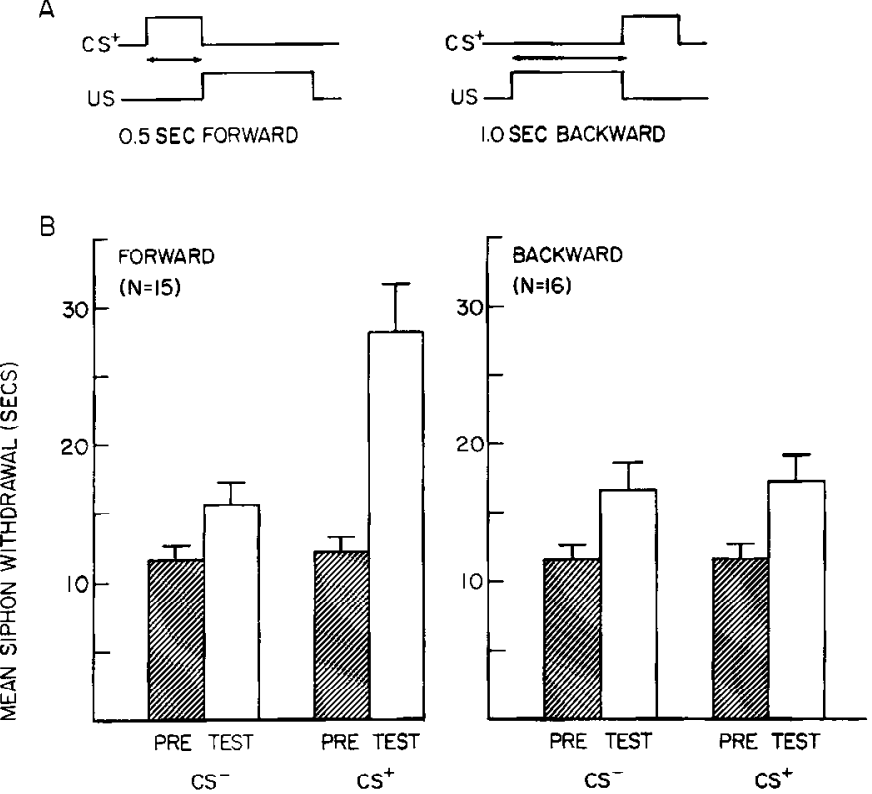

Figure 2. Comparison of forward and backward conditioning. $A$, Diagram illustrating the timing of the $C S^{+}$and the $U S$ during 0.5 sec forward and $1.0 \mathrm{sec}$ backward conditioning. $B$, Results of an experiment in which one group of animals received $0.5 \mathrm{sec}$ forward conditioning and another group received $1.0 \mathrm{sec}$ backward conditioning. Testing was carried out before (PRE) and $15 \mathrm{~min}$ after (TEST) 5 training trials. The animals receiving forward conditioning showed a small increase in responding to the $\mathrm{CS}^{-}$and a significantly greater increase in responding to the $\mathrm{CS}^{+}$ as a result of the training. This difference between the increase in responding to the $\mathrm{CS}^{+}$and the $\mathrm{CS}^{-}, \Delta \mathrm{CS}^{+}-\Delta \mathrm{CS}$, is our measure of associative learning. By contrast, animals receiving backward conditioning showed no difference in responding to the $\mathrm{CS}^{+}$and the $\mathrm{CS}^{-}$ following training. Data in this and all other figurcs arc cxpressed as means \pm SEM. electrodes. Both CSs and the US were delivered by hand, with the timing of the stimuli guided by electronically controlled audio signals. This procedure made it possible to train as many as 20 animals at a time and to test the animals 1 or more $d$ after the end of training. However, it introduced some inaccuracy in the $\mathrm{CS}^{+}-\mathrm{US}$ interval, particularly with short intervals. Therefore, in some experiments, animals were trained one at a time, with the CSs and the US delivered through fine insulated wires attached to no. 12 fish hooks implanted in the skin. In these experiments, current was passed between an implanted electrode and a ground electrode in the tank for the CS, or between two electrodes implanted in the tail for the US. Before training was begun, the intensity of each CS was adjusted to produce a siphon withdrawal lasting between 5 and $30 \mathrm{sec}$ (average current, $10 \mathrm{~mA}$ for the siphon and $23 \mathrm{~mA}$ for the mantle shelf). The average US current on the first trial of training was $240 \mathrm{~mA}$ measured in seawater.

The experiments consisted of three phases: (1) a pretest, (2) training, and (3) two retention tests, one approximately $15 \mathrm{~min}$ and the other 24 hr after training. (The experiments with implanted electrodes did not include a $24 \mathrm{hr}$ retention test.) In the pretest and each of the retention tests, the duration of siphon withdrawal was measured for each animal, first in response to the siphon CS and then in response to the mantle CS. Siphon withdrawal was measured with a stopwatch from stimulus onset until the siphon stopped contracting and began to relax. All responses were measured "blind" by an observer who did not know the experimental history of the animals. Animals were assigned to the different training conditions in such a way as to match their pretest scores. Training consisted of five trials with a $5 \mathrm{~min}$ intertrial interval (ITI), unless otherwise stated. On each trial, one $\operatorname{CS}\left(\mathrm{CS}^{+}\right)$was presented paired with the US and the other $\mathrm{CS}\left(\mathrm{CS}^{-}\right)$was presented specifically unpaired (Fig. 1). The $\mathrm{CS}^{+}$was the siphon stimulus for half of the animals in each group (Siphon ${ }^{+}$) and the mantle stimulus was the $\mathrm{CS}^{+}$for the other half (Mantle ${ }^{+}$). The interval between presentation of the $\mathrm{CS}^{+}$and the US (the interstimulus interval or ISI) was an experimental variable in the first set of experiments and was held constant at $0.5 \mathrm{sec}$ in the second set of experiments. The CS- was presented 2.5 min after the US, or halfway between the $\mathrm{CS}^{+}-\mathrm{US}$ presentations. Conditioning was assessed by comparing the change in responding to the $\mathrm{CS}^{+}$(postscore minus prescore, or $\left.\Delta \mathrm{CS}^{+}\right)$to the change in responding to the $\mathrm{CS}^{-}\left(\Delta \mathrm{CS}^{-}\right)$. Thus, each animal contributed a single conditioning score, $\Delta \mathrm{CS}^{+}-\Delta \mathrm{CS}^{-}$. This procedure allowed us to subtract any nonassociative effects from the effect of temporal pairing in each experiment. 


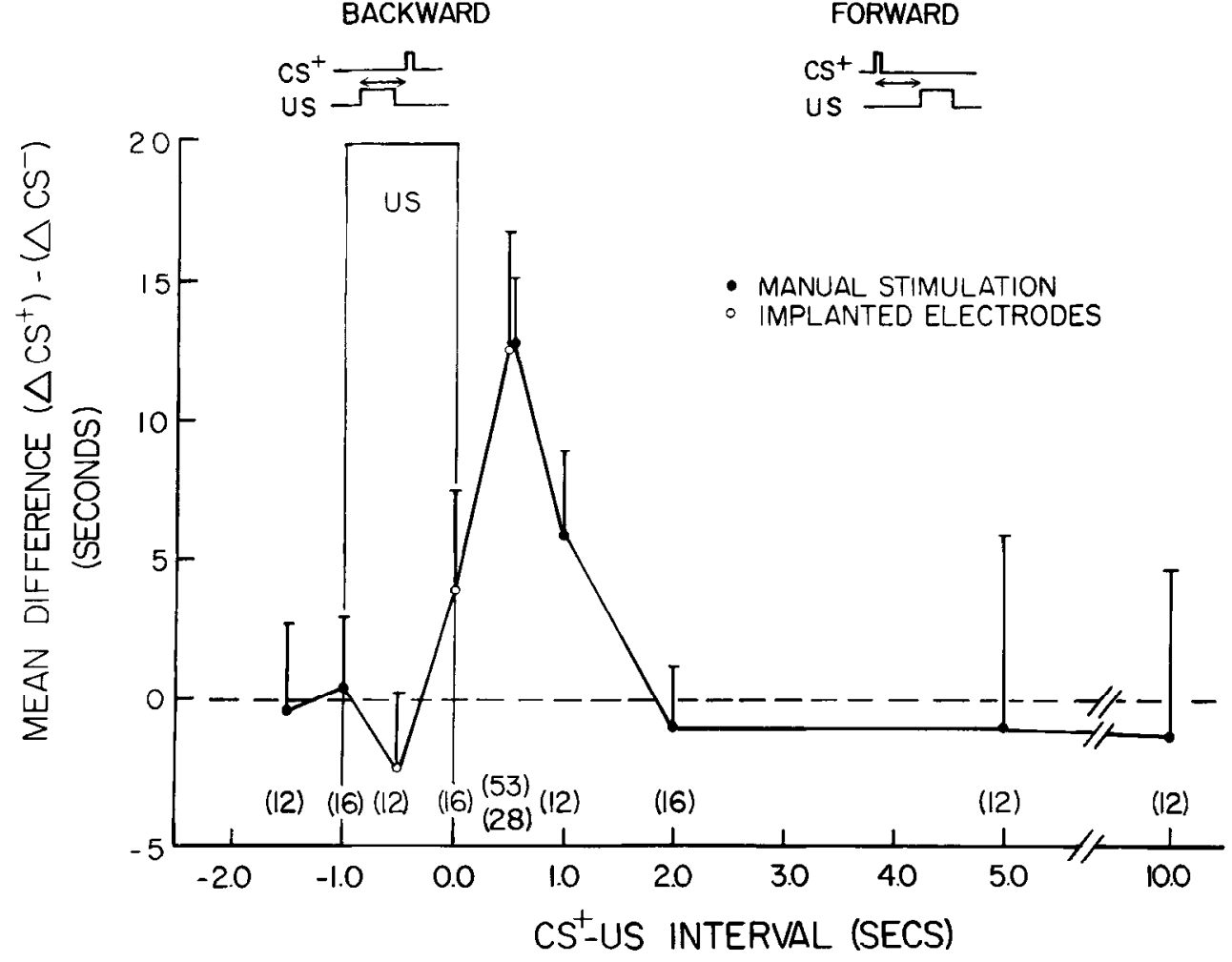

Figure 3. Interstimulus interval function. Summary of the results of a series of experiments similar to the onc shown in Figure 2, in which we measured associative learning $\left(\Delta \mathrm{CS}^{+}-\Delta \mathrm{CS}^{-}\right)$as a function of the time interval between the onset of the $\mathrm{CS}^{+}$and the US (the interstimulus interval). Negative $C S^{+}-U S$ intervals, Backward conditioning. Numbers in parentheses, The number of animals used to determine each data point. Of the intervals tested, the best conditioning was obtained when the $\mathrm{CS}^{+}$ preceded the US by $0.5 \mathrm{sec}$.
Occasional shipments of animals, although responsive and apparently healthy, did not show any evidence of conditioning (a shipment refers to animals that arrived from the same supplier at the same time, were housed and trained together, etc.). Since we expected some of our training conditions to produce no conditioning, we wished to be sure that animals in each shipment we used were capable of conditioning. We therefore trained randomly selected animals $(N \geq 4)$ in each shipment with a standard differential conditioning procedure (Carew et al., 1983) and excluded the results of an experiment if none of the groups of animals showed evidence of conditioning. This occurred for 3 of 18 shipments. Most experimental conditions were replicated with animals from at least two different shipments, and the results were pooled.

\section{Results}

Effect of interstimulus interval on conditioning of the siphon withdrawal reflex

We investigated the effect of the interstimulus interval by training different groups of animals with different $\mathrm{CS}^{+}-\mathrm{US}$ intervals and measuring the strength of conditioning. Our first experiment tested backward conditioning. Half of the animals in this experiment were trained with a $1.0 \mathrm{sec}$ back ward $\mathrm{CS}^{+}-\mathrm{US}$ interval (US onset preceded $\mathrm{CS}^{+}$onset by $1.0 \mathrm{sec}$ ), and half the animals were trained with a standard $0.5 \mathrm{sec}$ forward interval $\left(\mathrm{CS}^{+}\right.$onset preceded US onset by $0.5 \mathrm{sec}$ ). Each group also received a $\mathrm{CS}^{-}$ $2.5 \mathrm{~min}$ after the US (i.e., specifically unpaired). As expected, the animals receiving $0.5 \mathrm{sec}$ forward training showed a small increase in responding to the $\mathrm{CS}^{-}$, which we attribute to sensitization, and a significantly greater increase in responding to the $\mathrm{CS}^{+}$(Fig. 2). This difference between the increase in responding to the $\mathrm{CS}^{+}$and the $\mathrm{CS}^{-}\left(\Delta \mathrm{CS}^{+}-\Delta \mathrm{CS}^{-}\right)$is our measure of associative learning. Using this measure, a within-group comparison showed that animals receiving $0.5 \mathrm{sec}$ forward training exhibited significant associative learning (mean conditioning score $=12.2 \pm 3.5 \mathrm{SEM}, t_{14}=3.47, p<0.01$ ). By contrast, animals receiving $1.0 \mathrm{sec}$ backward training did not show evidence of associative learning (mean learning score $=0.4 \pm 2.5$, $t_{15}=0.17$, not significant). Moreover, a between-groups com- parison showed that conditioning for the $0.5 \mathrm{sec}$ forward group was significantly greater than that for the 1.0 sec backward group $\left(t_{29}=2.74, p<0.05\right)$. Since animals were randomly assigned to the two groups and were treated the same in all other respects, we conclude that training with a $1.0 \mathrm{sec}$ backward $\mathrm{CS}^{+}-\mathrm{US}$ interval produces little or no conditioning of the Aplysia siphon withdrawal reflex.

We next performed a series of experiments similar to the one illustrated in Figure 2, but with different $\mathrm{CS}^{+}-\mathrm{US}$ intervals (Fig. 3 , Table 1). Of the intervals tested, the best conditioning was obtained with the standard $0.5 \mathrm{sec}$ forward training (Fig. 3 and Table 1 show the average results from all replications of this condition). Marginal conditioning occurred with a $1.0 \mathrm{sec}$ forward interval $\left(t_{11}=2.00, p<0.05\right.$; one-tail), while there was no evidence of conditioning with forward intervals of 2.0, 5.0, or $10.0 \mathrm{sec}$, or backward intervals of 1.0 or $1.5 \mathrm{sec}$. The same pattern of results was obtained when animals were tested 15 min after training and when they were retested $24 \mathrm{hr}$ after training (Table 1). Control animals trained with a $0.5 \mathrm{sec}$ foward $\mathrm{CS}^{+}-\mathrm{US}$ interval did show significant differential conditioning both at 15 min and $24 \mathrm{hr}$ in each of these experiments $(p<$ 0.05 ; one-tail or lower in each case).

Since stimuli were delivered by hand in these experiments, the $\mathrm{CS}^{+}$-US interval was only accurate to within about $0.25 \mathrm{sec}$. This margin of error should not be important for longer intervals but could be a problem for intervals close to zero. In addition, training by hand allowed some possibility of experimenter bias. We therefore performed a second series of experiments in which we investigated the effect of conditioning with two additional $\mathrm{CS}^{+}-\mathrm{US}$ intervals $(0.5 \mathrm{sec}$ backward and simultaneous presentation of the $\mathrm{CS}^{+}$and US) with both CSs and the US delivered under electronic control through implanted electrodes. In addition, we trained half of the animals in these experiments with a $0.5 \mathrm{sec}$ forward $\mathrm{CS}^{+}-\mathrm{US}$ interval, which again produced significant differential conditioning (mean conditioning score $=$ $12.9 \pm 4.0, t_{27}=3.22, p<0.01$ ). By contrast, training with a $0.5 \mathrm{sec}$ backward interval produced no evidence of conditioning, 
Table 1. Interstimulus interval (ISI) function (within-group conditioning scores)

\begin{tabular}{|c|c|c|c|c|c|c|c|c|c|c|c|}
\hline \multirow{2}{*}{$\begin{array}{l}\text { ISI } \\
\text { (sec): }\end{array}$} & & \multicolumn{7}{|c|}{ Manual stimulation } & \multicolumn{3}{|c|}{ Implanted electrodes } \\
\hline & & -1.5 & -1.0 & 0.5 & 1.0 & 2.0 & 5.0 & 10.0 & -0.5 & 0.0 & 0.5 \\
\hline \multirow{3}{*}{$\begin{array}{l}15 \text { min } \\
\text { retention }\end{array}$} & $\bar{X}$ & -0.4 & 0.4 & $13.2^{a}$ & $6.0^{b}$ & -0.9 & -0.8 & -1.1 & -2.5 & 3.9 & $12.9^{a}$ \\
\hline & SEM & 3.1 & 2.5 & 2.0 & 3.0 & 2.2 & 6.9 & 6.0 & 2.8 & 3.7 & 4.0 \\
\hline & $N$ & 12 & 16 & 53 & 12 & 16 & 12 & 12 & 12 & 16 & 28 \\
\hline \multirow{3}{*}{$\begin{array}{l}24 \mathrm{hr} \\
\text { retention }\end{array}$} & $\bar{X}$ & -3.0 & -2.3 & $15.8^{a}$ & $9.5^{a}$ & 4.4 & 6.3 & 4.8 & & & \\
\hline & SEM & 2.3 & 3.2 & 3.1 & 2.7 & 3.9 & 5.7 & 6.6 & & & \\
\hline & $N$ & 12 & 16 & 53 & 12 & 16 & 12 & 12 & & & \\
\hline
\end{tabular}

${ }^{a} p<0.01$.

${ }^{b} p<0.05$; one-tailed.

while training with simultaneous presentation of the $\mathrm{CS}^{+}$and US produced a suggestion of conditioning that was not, however, statistically significant (Fig. 3, Table 1).

In experiments with either manual or implanted stimulation, the $\mathrm{CS}^{+}$pathway was the siphon for half of the animals and the mantle for the other half of the animals in each group. We have combined these conditions in the analysis thus far, since previous experiments had shown that conditioning with a $0.5 \mathrm{sec}$ forward $\mathrm{CS}^{+}-\mathrm{US}$ interval is approximately equal in both cases (Carew et al., 1983). However, it is possible that the CS+-US interval producing optimal conditioning depends on whether the siphon or mantle is the $\mathrm{CS}^{+}$. This seemed particularly likely in experiments with manual stimulation, where the stimuli to the siphon and mantle had different physical characteristics (i.e., brief tactile stimuli to the siphon and $0.5 \mathrm{sec}$ electrical stimuli to the mantle). In order to examine this question, we reanalyzed the data, comparing the siphon scores for the Siphon ${ }^{+}$animals to the siphon scores for the Mantle ${ }^{+}$animals (in which siphon stimulation was the $\mathrm{CS}^{-}$) to obtain an estimate of siphon conditioning. Similarly, we compared the mantle scores for the Mantle $^{+}$animals to the mantle scores for the Siphon ${ }^{+}$animals to get an estimate of mantle conditioning for each $\mathrm{CS}^{+}-\mathrm{US}$ interval. This analysis shows significant conditioning for both the siphon and the mantle with $0.5 \mathrm{sec}$ forward training and not with any other $\mathrm{CS}^{+}-\mathrm{US}$ interval (Table 2). Thus, the interstimulus interval function does not depend on whether the siphon or mantle is the $\mathrm{CS}^{+}$, within our limits of resolution.

The results of these experiments demonstrate an effect of temporal pairing or contiguity in conditioning of the Aplysia siphon withdrawal reflex similar to that seen in many instances of vertebrate conditioning, such as conditioning of the rabbit nictitating membrane response (Gormezano, 1972).
Effect of contingency on conditioning of the siphon withdrawal reflex

We investigated the effect of contingency by adding extra, unpaired or unpredicted USs during training. The basic experimental design is illustrated in Figure $4 A$. One group of animals received five trials of normal differential conditioning with a 5 min intertrial interval. A second group of animals (randomly selected from the same population as the first group) received exactly the same training, but in addition received five unpredicted USs interspersed among the training trials. Thus, both groups received the same number of pairings of the $\mathrm{CS}^{+}$and the US (the same amount of contiguity), but for the second group the US was less contingent on the $\mathrm{CS}^{+}$, that is, the $\mathrm{CS}^{+}$ was a poorer predictor that the US was about to occur.

The results of our first experiment with this design are shown in Figure $4 B$. (This figure and Fig. 5 show the data from the 24 hr posttest, at which time the CS and US strengths should have recovered from any habituation during training - see below; the data from the $15 \mathrm{~min}$ posttest were qualitatively similar, but were somewhat more variable.) As expected, the animals receiving normal training showed good differential conditioning (mean conditioning score $=15.6 \pm 3.0, p<0.01$ ). By contrast, animals receiving additional, unpredicted USs did not show significant conditioning (mean conditioning score $=6.6 \pm 4.5$ ). We have replicated this basic effect in three additional experiments with the same design but with different intertrial intervals or numbers of training trials (scc bclow and Tablc 3). In each case the result was the same: Animals receiving normal training showed significant conditioning, while animals receiving additional, unpredicted USs did not. When the data from all of these experiments are pooled, animals that received unpredicted USs

Table 2. ISI function (between-group conditioning scores)

\begin{tabular}{|c|c|c|c|c|c|c|c|c|c|c|c|}
\hline \multirow{2}{*}{$\begin{array}{l}\text { ISI } \\
\text { (sec): }\end{array}$} & & \multicolumn{7}{|c|}{ Manual stimulation } & \multicolumn{3}{|c|}{ Implanted electrodes } \\
\hline & & -1.5 & -1.0 & 0.5 & 1.0 & 2.0 & 5.0 & 10.0 & -0.5 & 0.0 & 0.5 \\
\hline \multirow[t]{3}{*}{ Siphon } & $\bar{X}$ & 4.8 & -1.4 & $11.0^{a}$ & 7.3 & -0.9 & -3.3 & 7.0 & -6.8 & 6.0 & $12.5^{b}$ \\
\hline & SEM & 4.2 & 2.6 & 2.2 & 4.7 & 4.8 & 8.1 & 4.9 & 9.3 & 7.2 & 6.9 \\
\hline & $N$ & 12 & 16 & 53 & 12 & 16 & 12 & 12 & 12 & 16 & 28 \\
\hline \multirow[t]{3}{*}{ Mantle } & $\bar{X}$ & -5.7 & 2.2 & $15.7^{a}$ & 4.7 & -0.9 & 1.7 & -9.2 & 1.8 & 1.9 & $13.3^{c}$ \\
\hline & SEM & 5.0 & 5.1 & 3.3 & 3.8 & 4.6 & 10.0 & 12.1 & 5.3 & 4.4 & 6.0 \\
\hline & $N$ & 12 & 16 & 53 & 12 & 16 & 12 & 12 & 12 & 16 & 28 \\
\hline
\end{tabular}

\footnotetext{
${ }^{a} p<0.01$.

${ }^{b} p<0.05$; one-tailed.

c $p<0.05$.
} 
A

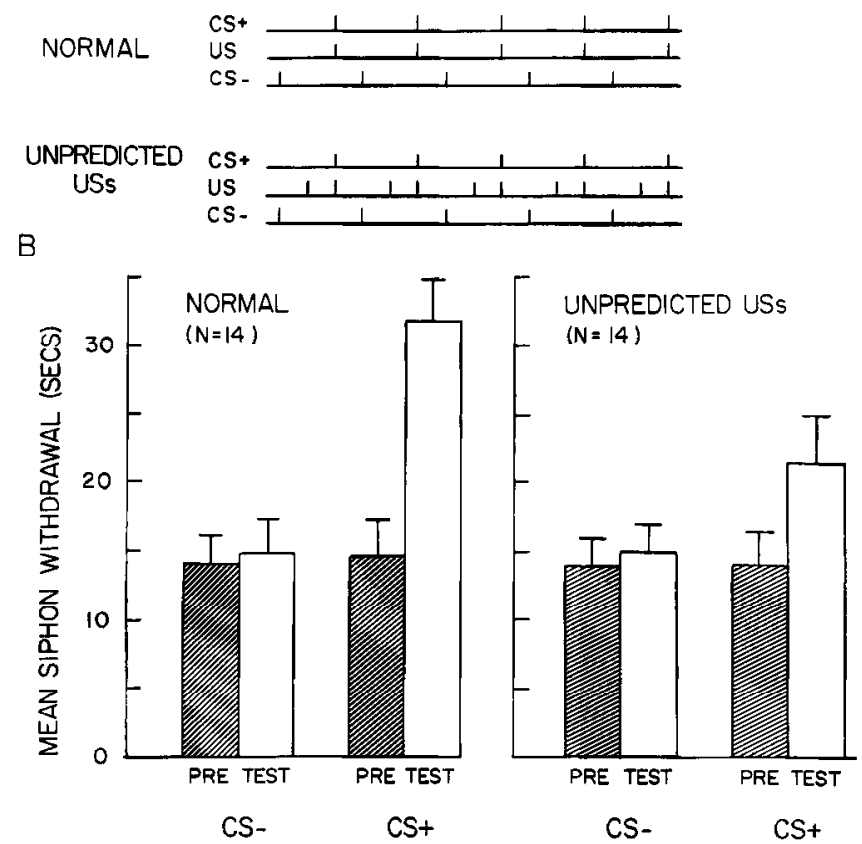

Figure 4. Comparison of normal conditioning and conditioning with extra, unpredicted USs. $A$, Diagram illustrating the training paradigms. $B$, Results of an experiment with this design in which one group of animals received five trials of normal differential conditioning, and another group received the same training plus five extra, unpredicted USs. Testing was carried out before and $24 \mathrm{hr}$ after training. Animals receiving normal training showed significant differential conditioning, while animals receiving unpredicted USs did not.

had significantly lower conditioning scores than the animals that received normal training (mean conditioning scores $=-0.5 \pm$ 2.2 and $11.3 \pm 1.8$, respectively; $t_{132}=4.18, p<0.01$ ) and, on average, showed no differential conditioning at all (Fig. 5). The lack of differential conditioning in the animals receiving unpredicted USs, compared to animals receiving normal training, was due to two effects: marginally greater responding to the $\mathrm{CS}^{-}$, which we would attribute to extra sensitization caused by the extra USs (mean $\Delta \mathrm{CS}^{-}=10.3 \pm 1.7$ for animals receiving unpredicted USs and $6.3 \pm 1.5$ for animals receiving normal training; $t_{132}=1.76, p<0.05$; one-tail), and significantly less responding to the $\mathrm{CS}^{+}$(mean $\triangle \mathrm{CS}^{+}=9.8 \pm 1.7$ for animals receiving unpredicted USs and $17.7 \pm 1.4$ for animals receiving normal training, $t_{132}=3.59, p<0.01$ ).

In the experimental design illustrated in Figure $4 A$, we altered the contingency of the US on the $\mathrm{CS}^{+}$while holding the number and timing of $\mathrm{CS}^{+}-\mathrm{US}$ pairings constant. In order to do this, we had to alter two other variables: the number of USs and the time between USs. To test whether these alterations, rather than the alteration in contingency, might account for the observed decrease in conditioning, we performed three additional experiments (Table 3). First, we were concerned that animals given unpredicted USs might not have conditioned because they received a higher frequency of USs (one every $2.5 \mathrm{~min}$, on average) than animals given normal training (one every $5 \mathrm{~min}$ ). However, US frequency does not appear to be a critical variable, since (1) animals given normal training with a $2.5 \mathrm{~min}$ ITI showed good conditioning (Table 3, Experiment B), and (2) animals given unpredicted USs with a $10 \mathrm{~min}$ ITI-thus receiving a US once every $5 \mathrm{~min}$, on average-still did not condition (Table 3, Experiment D). Second, it was possible that animals given unpredicted USs did not condition because they received more USs (10) than animals given normal training (five). However, ani-
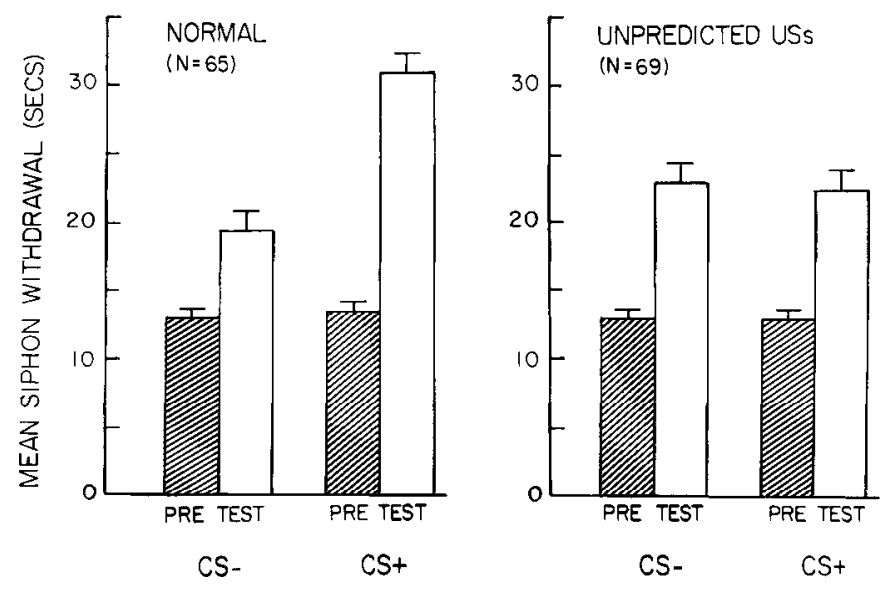

Figure 5. Pooled results from four experiments like the one shown in Figure 4, but with different ITIs or numbers of training trials (see Table 3). On average, animals receiving normal training showed significant differential conditioning, while animals receiving unpredicted USs showed no differential conditioning.

mals given 10 trials of normal training - and thus $10 \mathrm{USs}-$ also showed good conditioning (Table 3, Experiments C and D), which indicates that an increased number of USs per se does not interfere with conditioning. These results suggest that the decrease in conditioning by animals receiving unpredicted USs in each of these experiments was not due entirely to differences in US frequency or number, but rather, at least in part, to the difference in the degree to which the US was contingent on the $\mathrm{CS}^{+}$. In order to conclusively demonstrate an effect of contingency in Aplysia, however, it will be necessary to test that effect in other ways (e.g., Kamin, 1969; Rescorla, 1967).

\section{Discussion}

The results of our experiments indicate that conditioning of the Aplysia siphon withdrawal reflex is similar to conditioning in vertebrates in two major respects: the effects of ISI and contingency. The ISI function for conditioned siphon withdrawal (Fig. 3 ) is very similar to such functions for discrete skeletal responses in vertebrates, such as the rabbit nictitating membrane response (Smith et al., 1969), human eyeblink (Bernstein, 1934; McAllister, 1953), and human finger withdrawal (Spooner and Kellogg, 1947). In each of these cases, conditioning is optimal when the CS precedes the US by approximately $0.5 \mathrm{sec}$, and there is

\begin{tabular}{llccccc}
\hline $\begin{array}{l}\text { Table 3. } \\
\text { scores) }\end{array}$ & Effect of unpredicted USs (within-group conditioning \\
$\begin{array}{llllll}\text { Experi- } \\
\text { ment }\end{array}$ & USs & Trials & $\begin{array}{l}\text { ITI } \\
\text { (min) }\end{array}$ & $X$ & SEM & $N$ \\
\hline A & Normal & 5 & 5 & $15.6^{a}$ & 3.0 & 14 \\
& Unpredicted & 5 & 5 & 6.6 & 4.5 & 14 \\
B & Normal & 5 & 2.5 & $11.3^{a}$ & 3.6 & 24 \\
& Unpredicted & 5 & 5 & -2.5 & 3.9 & 26 \\
C & Normal & 10 & 5 & $6.9^{a}$ & 2.2 & 18 \\
& Unpredicted & 10 & 5 & -4.2 & 4.2 & 20 \\
D & Normal & 10 & 10 & $13.8^{b}$ & 5.7 & 9 \\
& Unpredicted & 10 & 10 & 2.7 & 2.8 & 9 \\
Total & Normal & - & - & $11.3^{a}$ & 1.8 & 65 \\
& Unpredicted & - & - & -0.5 & 2.2 & 69 \\
\hline
\end{tabular}

${ }^{a} p<0.01$

${ }^{b} p<0.05$. 
less or no conditioning with longer intervals, or when the US precedes the CS during training (for reviews, see Gormezano, 1972; Kimble, 1961; Mackintosh, 1974). The results of our experiments on the effect of contingency are also qualitatively similar to the results of analogous experiments with rats (Rescorla, 1968). Conditioning of the nudibranch mollusc Hermissenda shows a similar effect of contingency (Farley and Kern, in press), and conditioning of another gastropod mollusc, Limax maximus, shows three other features of vertebrate conditioning: a US pre-exposure effect, second-order conditioning, and blocking (Sahley et al., 1981). A form of blocking has also recently been demonstrated in Aplysia (Colwill, 1985).

In addition to these similarities, there are also some differences between conditioning of the Aplysia siphon withdrawal reflex and vertebrate conditioning. For example, many vertebrate behaviors show either a tight interstimulus interval function (e.g., Smith et al., 1969) or a strong effect of contingency (Rescorla, 1968), but not both. Furthermore, it often takes more than five trials to establish an effect of contingency in vertebrates (e.g., Rescorla, 1968). Finally, vertebrate conditioning sometimes involves the appearance of a new response, rather than the strengthening of a preexisting response (e.g., Gormezano, 1972). We do not feel that this difference is fundamental, however, since in several cases, neurophysiological experiments in vertebrates have shown that conditioning simply strengthens a preexisting neural response until it is above threshold for producing an observable behavioral response (e.g., Cegavske et al., 1979). On balance, therefore, we feel that the similarities between conditioning in molluscs and in vertebrates are more important than the differences, which suggests that similar neuronal mechanisms could underlie conditioning in these different phyla.

In addition to providing a test of generality, our behavioral results also place constraints on possible cellular mechanisms of the conditioning. The neuronal mechanism we believe underlies conditioning of the Aplysia siphon withdrawal reflex is activity-dependent amplification of presynaptic facilitation. In brief, the US in our behavioral experiments produces presynaptic facilitation of transmitter release from sensory neurons in the CS pathway. This facilitation involves a sequence of steps that includes stimulation of an adenyl cyclase and elevation of cAMP levels in the sensory neurons (see Kandel and Schwartz, 1982). We have found that the facilitation is amplified if there is spike activity in the CS sensory neurons just before the US is delivered, as occurs during behavioral conditioning, and we believe this is a cellular mechanism of the conditioning (Hawkins et al., 1983; see also Walters and Byrne, 1983). Preliminary experiments suggest that this amplification of facilitation may be due to "priming" of the adenyl cyclase by $\mathrm{Ca}^{2+}$, which enters the sensory neuron during the spike activity, so that the cyclase produces more cAMP in response to the US (Abrams et al., 1983; Kandel et al., 1983; Ocorr et al,, 1985). If this amplification of facilitation is, in fact, a mechanism of the conditioning, we would predict that it should have the same ISI function as the behavior. Preliminary data indicate that forward pairing of spike activity and the US is more effective than backward pairing (Clark, 1984). We do not yct understand why spike activity in the sensory neurons has to occur shortly before the US is delivered to amplify its effectiveness, but we hope that a more detailed understanding of the molecular mechanism of the conditioning will provide an explanation for this temporal requirement.

We also do not yet have any experimental evidence concerning the neuronal mechanism of the effect of contingency. That effect actually seems contrary to the neuronal mechanism of conditioning proposed above, which might be expected to predict that presentation of extra USs should simply produce more facilitation. Rescorla and Wagner (1972) have suggested that the effect of contingency is due to conditioning of background stimuli, which blocks conditioning of the experimental CS. Recent behavioral evidence from Aplysia tends to support this idea (Colwill, 1985). Hawkins and Kandel (1984) have attempted to translate Rescorla and Wagner's hypothesis into a neuronal model based on known Aplysia circuitry. They have also proposed a somewhat simpler hypothesis, which is that repeated presentations of the US may lead to habituation of its effectiveness, perhaps due to synaptic depression in the US pathway. A quantitative simulation based on this idea has produced results similar to the results shown in Figure 5 (Hawkins and Kandel, 1984). This hypothesis is probably somewhat simplistic, however, and we doubt that it can provide a complete explanation for the effect of contingency. We mention it primarily to illustrate a more general idea, which is that the neural mechanisms of higherorder features of learning, such as the effect of contingency, may be built by putting together combinations of the mechanisms of simpler forms of learning, such as synaptic depression and activity-dependent facilitation. At the moment, this proposal is speculative, but we hope that it will provide a useful framework for further investigations into the neuronal mechanisms of learning.

\section{References}

Abrams, T. W., T. J. Carew, R. D. Hawkins, and E. R. Kandel (1983) Aspects of the cellular mechanism of temporal specificity in conditioning in Aplysia: Prcliminary evidence for $\mathrm{Ca}^{2+}$ influx as a signal of activity. Soc. Neurosci. Abstr. 9: 168.

Bernstein, A. L. (1934) Temporal factors in the formation of conditioned eyelid reactions in human subjects. J. Gen. Psychol. 10: 173197.

Carew, T. J., E. T. Walters, and E. R. Kandel (1981) Classical conditioning in a simple withdrawal reflex in Aplysia californica. J. Neurosci. 1: 1426-1437.

Carew, T. J., R. D. Hawkins, and E. R. Kandel (1983) Differential classical conditioning of a defensive withdrawal reflex in Aplysia californica. Science 219: 397-400.

Cegavske, C. F., M. M. Patterson, and R. F. Thompson (1979) Neuronal unit activity in the abducens nucleus during classical conditioning of the nictitating membrane response in the rabbit (Oryctolagus cuniculus). J. Comp. Physiol. Psychol. 93: 595-609.

Clark, G. A. (1984) A cellular mechanism for the temporal specificity of classical conditioning of the siphon-withdrawal response in Aplysia. Soc. Neurosci. Abstr. 10: 268.

Colwill, R. M. (1985) Context conditioning in Aplysia californica. Soc. Neurosci. Abstr. 11: 796.

Farley, J., and G. Kern (in press) Contingency-sensitive behavioral change in Hermissenda: Temporally-specific attenuation of conditioning. Anim. Learn. Behav.

Gormezano, I. (1972) Investigations of defense and reward conditioning in the rabbit. In Classical Conditioning, Vol. 2: Current Research and Theory, A. H. Black and W. F. Prokasy, eds., pp. 151181, Appleton-Century-Crofts, New York.

Hawkins, R. D., and E. R. Kandel (1984) Is there a cell biological alphabet for simple forms of lcarning? Psychol. Rev. 91: 375-391.

Hawkins, R. D., T. W. Abrams, T. J. Carew, and E. R. Kandel (1983) A cellular mechanism of classical conditioning in Aplysia: Activitydependent amplification of presynaptic facilitation. Science 219:400405.

Hawkins, R. D., T. J. Carew, and E. R. Kandel (1983) Effects of interstimulus interval and contingency on classical conditioning in Aplysia. Soc. Neurosci. Abstr. 9: 168.

Kamin, L. J. (1969) Predictability, surprise, attention and conditioning. In Punishment and Aversive Behavior, B. A. Campbell and R. M. Church, eds., pp. 279-296, Appleton-Century-Crofts, New York.

Kandel, E. R., and J. H. Schwartz (1982) Molecular biology of learning: Modulation of transmitter release. Science 218: 433-443.

Kandel, E. R., T. Abrams, L. Bernier, T. J. Carew, R. D. Hawkins, and J. H. Schwartz (1983) Classical conditioning and sensitization share 
aspects of the same molecular cascade in Aplysia. Cold Spring Harbor Symp. Quant. Biol. 48: 821-830.

Kimble, G. A. (1961) Hilgard and Marquis' Conditioning and Learning, Appleton-Century-Crofts, New York.

Mackintosh, N. J. (1974) The Psychology of Animal Learning, Academic, New York.

McAllister, W. R. (1953) Eyelid conditioning as a function of the CSUS interval. J. Exp. Psychol. 45: 417-428.

Ocorr, K. A., E. T. Walters, and J. H. Byrne (1985) Associative conditioning analog selectively increases cAMP levels of tail sensory neurons in Aplysia. Proc. Natl. Acad. Sci. USA 82: 2548-2552.

Rescorla, R. A. (1967) Pavlovian conditioning and its proper control procedures. Psychol. Rev. 74: 71-80.

Rescorla, R. A. (1968) Probability of shock in the presence and absence of CS in fear conditioning. J. Comp. Physiol. Psychol. 66: 1-5.

Rescorla, R. A., and A. R. Wagner (1972) A theory of Pavlovian conditioning: Variations in the effectiveness of reinforcement and nonreinforcement. In Classical Conditioning, Vol. 2: Current Research and Theory, A. H. Black and W. F. Prokasy, eds., pp. 64-99, Appleton-Century-Crofts, New York.

Sahley, C., J. W. Rudy, and A. Gelperin (1981) An analysis of associative learning in a terrestrial mollusc. I. Higher-order conditioning, blocking, and a transient US pre-exposure effect. J. Comp. Physiol. 144: 1-8.

Smith, M. C., S. R. Coleman, and I. Gormezano (1969) Classical conditioning of the rabbit nictitating membrane response at backward, simultaneous, and forward CS-US intervals. J. Comp. Physiol. Psychol. 69: 226-231.

Spooner, A., and W. N. Kellogg (1947) The backward-conditioning curvc. Am. J. Psychol. 60: 321-334.

Walters, E. T., and J. H. Byrne (1983) Associative conditioning of single sensory neurons suggests a cellular mechanism for learning. Science 219: 405-408. 